OPEN ACCESS

Edited by:

Hyun Park,

National Cancer Institute (NCl),

United States

Reviewed by:

Sheela Ramanathan,

Université de Sherbrooke, Canada

Nu Zhang,

The University of Texas Health Science

Center at San Antonio,

United States

Subburaj llangumaran,

Université de Sherbrooke, Canada

*Correspondence: Jae-Ho Cho

jh_cho@chonnam.ac.kr

Specialty section:

This article was submitted to

T Cell Biology,

a section of the journal

Frontiers in Immunology

Received: 13 October 2020 Accepted: 14 December 2020

Published: 28 January 2021

Citation:

Lee G-W, Lee S-W, Kim J, Ju Y-J, Kim H-O, Yun C-H and Cho J-H (2021) Supraphysiological Levels of IL-2 in Jak3-Deficient Mice Promote Strong Proliferative Responses of Adoptively

Transferred Naive CD8 ${ }^{+} T$ Cells.

Front. Immunol. 11:616898.

doi: 10.3389/fimmu.2020.616898

\section{Supraphysiological Levels of IL-2 in Jak3-Deficient Mice Promote Strong Proliferative Responses of Adoptively Transferred Naive CD8 ${ }^{+}$T Cells}

\author{
Gil-Woo Lee ${ }^{1,2,3}$, Sung-Woo Lee 1,2,3, Juhee Kim ${ }^{1}$, Young-Jun $\mathrm{Ju}^{4}$, Hee-Ok Kim ${ }^{3}$, \\ Cheol-Heui Yun ${ }^{4}$ and Jae-Ho Cho ${ }^{2,3 *}$
}

${ }^{1}$ Division of Integrative Biosciences and Biotechnology, Pohang University of Science and Technology, Pohang, South Korea, ${ }^{2}$ Medical Research Center for Combinatorial Tumor Immunotherapy, Department of Microbiology and Immunology, Chonnam National University Medical School, Jeonnam, South Korea, ${ }^{3}$ Immunotherapy Innovation Center, Chonnam National University Medical School, Hwasun Hospital, Jeonnam, South Korea, ${ }^{4}$ Department of Agricultural Biotechnology and Research Institute of Agriculture and Life Sciences, Seoul National University, Seoul, South Korea

The antigen-independent, strong proliferative responses of naive $\mathrm{CD} 8^{+} \mathrm{T}$ cells have been well demonstrated in a particular strain of mice lacking IL-2 receptors. This type of proliferation is mainly driven by common gamma-chain $\left(\gamma_{c}\right)$ cytokines, such as IL-2, IL-7, and IL-15, present at abnormally high levels in these mice. Similarly, in the present study, we showed that mice lacking Janus kinase 3 (Jak3), a tyrosine kinase crucial for $\gamma_{c}$ cytokine signaling, could induce strong proliferation of adoptively transferred naive CD8 ${ }^{+} \mathrm{T}$ cells. This proliferation was also independent of antigenic stimulation, but heavily dependent on IL-2, as evidenced by the failure of proliferation of adoptively transferred IL-2 receptor alpha- and beta-chain-deficient naive $\mathrm{CD}^{+} \mathrm{T}$ cells. Consistent with this, $\mathrm{Jak3}^{-/-}$mice showed elevated serum levels of IL-2 compared to wild-type mice, and interestingly, IL-2 production was due to high levels of accumulation of activated CD4 ${ }^{+} \mathrm{T}$ cells in $\mathrm{Jak3}^{-/}$mice along with defective $\mathrm{CD} 4^{+} \mathrm{T}$ regulatory cells. Collectively, these findings reveal previously unidentified unique immune contexts of $\mathrm{Jak}^{-/-}$mice that cause robust IL-2-driven T cell expansion and have a clinical implication for designing a treatment strategy for human patients with loss-of-function genetic mutations of Jak3.

Keywords: interleukin-2, naive CD8 ${ }^{+} \mathrm{T}$ cells, antigen-independent proliferation, Janus kinase 3 , activated $\mathrm{CD}^{+}{ }^{+} \mathrm{T}$ cells, CD4+ regulatory $\mathrm{T}$ cells

\section{INTRODUCTION}

Janus kinase 3 (Jak3) is a member of the Janus family of protein tyrosine kinases and is specifically associated with a cytoplasmic domain of the common receptor gamma-chain $\left(\gamma_{c}\right)$ shared by cytokines such as IL-2, IL-4, IL-7, IL-9, IL-15, and IL-21 $(1,2)$. When these cytokines bind to their specific receptors containing $\gamma_{c}$, Jak3 is activated and initiates a cascade of signal transduction 
through the phosphorylation of signal transducer and activator of transcription (STAT) proteins to induce the expression of various genes and subsequent biological functions (3-5). Based on these roles of $\gamma_{c}$ cytokines, Jak3-deficient mice have several abnormalities similar to those observed in mice lacking $\gamma_{c}$ cytokines and their corresponding receptors (6-8). In particular, defects of T and B cells and NK cells typically observed in mice lacking Jak3 can be largely attributed to failures in inducing IL-7 and IL-15 signaling, respectively (9-11). Likewise, defects in the development of $\mathrm{CD}^{+}{ }^{+} \mathrm{T}$ regulatory cells (Tregs) are also apparent in Jak3-deficient mice owing to the inability to induce IL-2 signaling that is involved in the development, maintenance, and function of Tregs (12).

Although all these aforementioned alterations are adequately documented in both mice and humans lacking functional Jak3, the human cases are in general more clearly associated with severe combined immunodeficiency (13-15). Thus, Jak3deficient mice, unlike patients with loss-of-function mutations of Jak3 (16), are not completely lymphopenic for $\mathrm{T}$ cells in particular, but their numbers (for $\mathrm{CD} 4^{+}$but not $\mathrm{CD} 8^{+} \mathrm{T}$ cells) are almost fully restored over time with age $(9,10,17)$. Moreover, the $\mathrm{T}$ cells restored in Jak3-deficient mice have been shown to display an activated $\mathrm{T}$ cell phenotype, such as high and low levels of CD44 and CD62L, respectively (9). Although these large numbers of activated $\mathrm{T}$ cells are likely to be associated with a defect in Treg-mediated immunosuppression in Jak3-deficient mice $(12,18)$, whether these cells indeed contribute to shaping altered immune contexts in these mice remains to be addressed.

In this study, we focused on this issue by investigating proliferative responses of naive $\mathrm{CD}^{+}$and $\mathrm{CD}^{+} \mathrm{T}$ cells adoptively transferred into Jak3-deficient mice. We demonstrated that these mice have a unique IL-2-rich immune environment and thus stimulate a fast and robust form of antigen-independent, but IL-2-dependent, $\mathrm{T}$ cell proliferative responses. Our findings highlight the important role of Jak3 in restraining the spontaneous activation of $\mathrm{CD}^{+} \mathrm{T}$ cells and thus lowering the production of in vivo IL-2 below a certain physiological level at which abnormal $\mathrm{T}$ cell proliferation is inhibited while Tregs homeostasis is preserved.

\section{METHODS}

\section{Mice}

C57BL/6 (B6), B6.PL (Thy1.1), B6.SJL (Ly5.1) mice were purchased from the Jackson Laboratory. Sources of Foxp3eGFP mice and OT-I, 2C, 2C.Cd $25^{-/-}, 2 \mathrm{C} . \mathrm{Cd} 122^{-/-}$, OT-II, and SMARTA TCR Tg mice were previously described $(19,20)$ and obtained from Pohang University of Science and Technology (POSTECH). $\mathrm{Jak3}^{-/-}$mice (9) were also obtained from POSTECH, and generated and maintained by crossing with $\mathrm{Jak3}^{+/-}$mice. $\mathrm{Jak3}^{+/+}$or $\mathrm{Jak3}^{+/-}$mice were used as a littermate control. Unless it is described, 8-10 weeks old mice were used for the experiments according to the protocols approved by the Institutional Animal Care and Use Committee of the Chonnam National University.

\section{T Cell Purification}

Pooled (inguinal, axillary, cervical and mesenteric) lymph node (LN) cells from the indicated mice were prepared for cell sorting as previously described (20). In brief, LN cells were first depleted of non-T cells by using the following biotinylated antibodies; CD11b, CD11c, CD24, CD19, B220, NK1.1 and IMag according to the manufacturer's protocol (BD Biosciences). Enriched T cells were stained with fluorochrome conjugated antibodies to $\mathrm{CD} 8 \alpha, \mathrm{CD} 4, \mathrm{CD} 25, \mathrm{CD} 44$, and CD62L for obtaining either CD $4^{+}$ $\mathrm{CD} 25^{-} \mathrm{CD}_{4} 4^{\text {lo }} \mathrm{CD} 62 \mathrm{~L}^{\mathrm{hi}}$ (naive $\mathrm{CD} 4^{+}$) or $\mathrm{CD} 8 \alpha^{+} \mathrm{CD} 44^{\text {lo }}$ $\mathrm{CD}_{2} \mathrm{~L}^{\text {hi }}$ (naive $\mathrm{CD}^{+}$), or in some experiment Foxp3-eGFP ${ }^{+}$ $\mathrm{CD}^{+}\left(\mathrm{CD}^{+}\right.$Tregs), and then sorted by using a FACS AriaII (BD Biosciences) or Moflo XDP (Beckman Coulter, Brea, CA, USA) to $>95 \%$ purity.

\section{Adoptive Transfer}

After purification, $\mathrm{T}$ cells were labeled with $5 \mu \mathrm{M}$ of CFSE (Invitrogen) as previously described (20) and injected intravenously (i.v.) into the indicated hosts. For inducing lymphopenia, the indicated mice were treated with $700 \mathrm{rad}$ of whole-body irradiation (1 day before adoptive transfer).

\section{Flow Cytometry Analysis}

Single-cell suspensions were prepared from lymph nodes and spleens, and were pressed and filtered through cell strainers. For surface staining, isolated cells were stained with the following fluorochrome-conjugated $\mathrm{mAbs}$ from Biolegend, eBioscience, or TONBO: CD3 (145-2C11), CD4 (GK1.5 and RM4-5), CD8 $\alpha$ (53-6.7), CD25 (PC61.5), CD44 (IM7), CD45.1 (A20), CD45.2 (104), CD62L (MEL-14), CD90.1 (HIS51 or OX-7), and 2C TCR clonotype (1B2) (19). Propidium iodide (PI) (Sigma Aldrich) was used at $500 \mathrm{ng} / \mathrm{ml}$ of final concentration for staining of $1-5 \times 10^{6}$ of cells to label dead cells. Flow cytometry samples were run using a LSRII or FACSCanto II (BD Biosciences) and analyzed by FlowJo software (Tree Star).

\section{Administration of Antibodies In Vivo}

For the in vivo $\mathrm{CD} 4^{+} \mathrm{T}$ cell depletion experiment, $100 \mu \mathrm{g}$ of anti$\mathrm{CD} 4 \mathrm{mAb}$ (GK1.5) was injected intraperitoneally (i.p.) four times every 2 days for 7 days before adoptive cell transfer into Jak $3^{-1-}$ hosts.

\section{Cytokine ELISA}

For detection of in vivo IL-2, sera from the indicated mice were collected and analyzed by a standard protocol using a cytokine sandwich ELISA kit for IL-2 (BD Biosciences) according to the manufacturer's instructions.

\section{Direct Intracellular Cytokine Staining for In Vivo IL-2 Production}

As previously described (21), $250 \mu \mathrm{g}$ brefeldin A (Sigma-Aldrich) was injected i.v. into $\mathrm{Jak3}^{+/+}$and $\mathrm{Jak3}^{-/-}$mice. Six hours later, mice were sacrificed, and single-cell suspensions were prepared from 
spleens on ice in the presence of $10 \mu \mathrm{g} / \mathrm{ml}$ brefeldin A. Splenocytes were immediately Fc-blocked (anti-CD16/32; BD Biosciences) without any exogenous stimulus, surface stained with CD4, $\mathrm{CD} 8 \alpha, \mathrm{CD} 44$, and CD62L, fixed and permeabilized with CytoFix/CytoPerm (BD Biosciences), and stained for intracellular cytokine IL-2 (JES6-5H4; BD Biosciences) for flow cytometry.

\section{Real-Time (RT) PCR}

$1-2 \times 10^{6}$ spleen cells or FACS-purified $\mathrm{CD} 4^{+} \mathrm{T}$ cells from the indicated mice were used for RNA extraction with NucleoZOL (Macherey-Nagel) and stored at $-80{ }^{\circ} \mathrm{C}$ before the further steps. Isolation of mRNA was done according to the manufacturer's instructions. cDNA was synthesized with the M-MLV reverse transcriptase and oligo dT (TAKARA). Real-time RT-PCR was performed with the TaqMan Gene Expression Master Mix using StepOnePlus Real-Time PCR System with TaqMan probe for Il2 mRNA (Mm00434256_m1; Applied Biosystems).

\section{Statistical Analysis}

An unpaired two-tailed Student's $t$-test was performed to test statistical significance using Prism (GraphPad Software). Differences in mean values were considered statistically significant at a $P$ value of less than 0.05 .

\section{RESULTS}

\section{Robust Proliferative Responses of Naive T Cells in Jak3 ${ }^{-/-}$Hosts}

Given the functional association of Jak3 for mediating the signal transduction of $\gamma_{c}$ cytokines, it has been previously demonstrated that mice lacking Jak3 (or its binding receptor CD132) have a defect in $\mathrm{T}$ cell development, especially the $\mathrm{CD}^{+} \mathrm{T}$ cell population, due to IL-7 signaling failure $(9,10,17)$. To further examine the altered immune contexts of these mice, we adoptively transferred FACS-purified, CFSE-labeled C57BL/6 (B6) naive $\mathrm{CD}^{+}$or $\mathrm{CD}^{+} \mathrm{T}$ cells into $\mathrm{Jak}^{-1-}$ mice (Figure 1A). Notably, the donor $\mathrm{CD} 4^{+}$and $\mathrm{CD}^{+} \mathrm{T}$ cells showed marked proliferation from day 3 and a more potent response on day 7 , as evidenced by CFSE dye dilution (Figure 1B, bottom, and Supplementary Figure 1A). As a control, when compared to > 6 divisions in $\mathrm{Jak3}^{-/-}$mice, the donor cells adoptively transferred into irradiated B6 mice (700 rad) showed only 2-3 rounds of cell divisions (Figure 1B, top, and Supplementary Figure 1A). These data suggest that the tempo and type of proliferation of $\mathrm{T}$ cells observed in $\mathrm{Jak3}^{-/-}$mice are distinctly different from the typically slow rate of lymphopenia-induced homeostatic proliferation (LIP) (22).

To examine whether the aforementioned fast and robust proliferative responses are dependent on abnormal stimulation by undefined antigens that may be present in $J a k 3^{-/-}$hosts, we performed the adoptive transfer experiment using monoclonal $\mathrm{T}$ cell receptor (TCR) transgenic $\mathrm{CD}^{+}$or $\mathrm{CD}^{+} \mathrm{T}$ cells. Jak3 $3^{-/-}$ mice were co-transferred with a mixture of either OT-II and
SMARTA CD4 ${ }^{+} \mathrm{T}$ cells (specific for $\mathrm{I}-\mathrm{A}^{\mathrm{b}}$-restricted ovalbumin 323-339 and lymphocyte choriomeningitis virus glycoprotein 61-80 peptide, respectively) or $2 \mathrm{C}$ and OT-I $\mathrm{CD}^{+} \mathrm{T}$ cells (specific for $\mathrm{H}-2 \mathrm{~K}^{\mathrm{b}}$-restricted SIYRYYGL peptide and ovalbumin 257-264 peptide, respectively) (Figure 1C). All donor cells showed proliferation, although to varying extents depending on their intrinsic self-reactivity-known to be correlated with expression levels of CD5, a negative regulator of TCR signaling, i.e., SMARTA > OT-II, and OT-I > 2C (2325) - with SMARTA and OT-I donors demonstrating a greater proliferation than OT-II and 2C donors, respectively (Figure 1D and Supplementary Figure 1B). These findings suggest that the strong $\mathrm{T}$ cell proliferative response observed in $\mathrm{Jak3}^{-/-}$hosts is antigen-independent but dependent on tonic TCR contacts with self-ligands.

\section{Role of $\gamma_{c}$ Cytokines in Naive T Cell Expansion in $\mathrm{Jak3}^{-/-}$Hosts}

Given the antigen-independent strong $\mathrm{T}$ cell proliferation in $J a k 3^{-/-}$hosts, we next examined the involvement of certain $\gamma_{c}$ cytokines, especially IL-2 and IL-15, both of which have been shown to induce antigen-independent robust $\mathrm{T}$ cell proliferation (19). To this end, a mixture of FACS-purified, CFSE-labeled Cd122-/- (IL-2 receptor beta-chain shared for IL2 and IL-15) and wild-type (WT) naive $2 \mathrm{C} \mathrm{CD} 8^{+} \mathrm{T}$ cells was cotransferred into $\mathrm{Jak3}^{-/-}$or control $\mathrm{Jak}^{+/-}$hosts (Figure 2A). At day 7 after transfer, in control $\mathrm{Jak3}^{+/-}$hosts, both WT and Cd122 $2^{-/-}$2C donor cells remained undivided (Figure 2B, top left two). However, in Jak3 ${ }^{-/-}$hosts, while WT 2C donor cells showed strong proliferative responses, $\mathrm{Cd} 122^{-/-} 2 \mathrm{C}$ donor cells failed to proliferate (Figure 2B, top right two, and Supplementary Figure 2). When this adoptive transfer experiment was repeated in the same but irradiated (700 rad) hosts, both WT and $C d 122^{-/-} 2 \mathrm{C}$ donors showed similar degrees of slow LIP in control $\mathrm{Jak3}^{+/-}$hosts (Figure 2B, bottom left two), which is known to be IL-7 (and self)dependent (26-29). However, in irradiated Jak3 ${ }^{-1-}$ hosts, WT $2 \mathrm{C}$ donor cells showed markedly faster and greater proliferative responses than $\mathrm{Cd} 122^{-/-} 2 \mathrm{C}$ donor cells showing only slow rate of LIP (Figure 2B, bottom right two, and Supplementary Figure 2), suggesting a role of CD122-dependent cytokines other than IL-7.

The implication from the above data with $C d 122^{-/-}$cells as a donor is that IL-2 and/or IL-15 are crucial requirements for

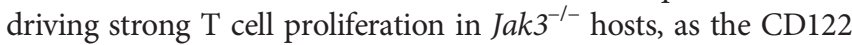
is a receptor subunit shared for both IL-2 and IL-15. To further examine whether both cytokines are equally required, we performed the same aforementioned adoptive transfer experiments with CD25 (IL-2 receptor alpha-chain)-deficient 2C cells as the donor. For this purpose, a mixture of FACS-purified, CFSE-labeled $\mathrm{Cd}_{25^{-/}}$and WT naive $2 \mathrm{C} \mathrm{CD8}{ }^{+} \mathrm{T}$ cells was cotransferred into $\mathrm{Jak3}^{-/-}$or control Jak3 ${ }^{+/-}$hosts (Figure 3A). WT $2 \mathrm{C}$ donor cells showed robust proliferation at day 7 in $\mathrm{Jak3}^{-/-}$ hosts; however, $\mathrm{Cd} 25^{-/-} 2 \mathrm{C}$ donor cells remained undivided (Figure 3B, top right two, and Supplementary Figure 3). 
A

C

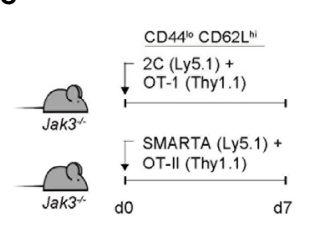

B

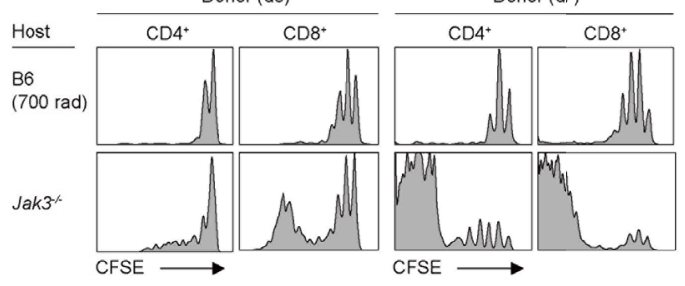

D
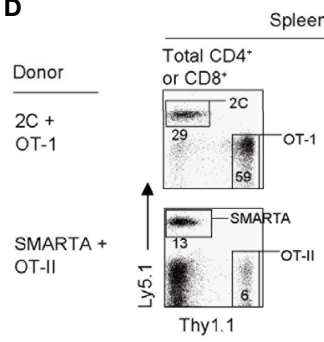

Spleen cells from Jak3\% host (d7)

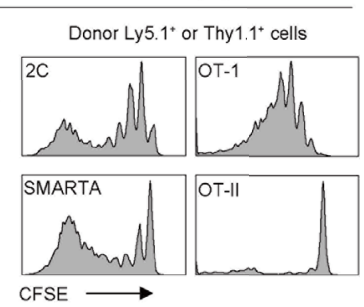

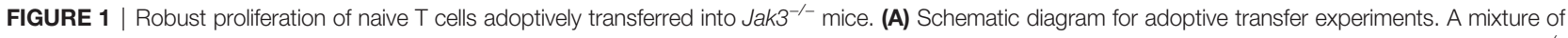
CFSE-labeled naive $\mathrm{CD} 4^{+}$and $\mathrm{CD} 8^{+} \mathrm{T}$ cells purified from B6 mice (Thy1.1) was co-injected i.v. into either irradiated (700 rad) B6 mice or unmanipulated Jak3 ${ }^{-/-}$mice $\left(1 \times 10^{6}\right.$ cells for each donor per mouse; $n=3-5$ mice). (B) Spleen cells of the recipient mice were analyzed on days 3 and 7 for CFSE dilution by flow cytometry. (C) Schematic diagram for adoptive transfer experiments. A mixture of FACS-purified CFSE-labeled either naive 2C (Ly5.1) and OT-I (Thy1.1) CD8 ${ }^{+}$or naive OT-II (Thy1.1) and SMARTA (Ly5.1) CD4 ${ }^{+}$T cells was co-injected i.v. into Jak3 ${ }^{-/-}$mice $\left(0.5-1 \times 10^{6}\right.$ cells for each donor per mouse; $n=2-3$ mice). (D) Spleen cells of the recipient mice were analyzed on day 7 for CFSE dilution by flow cytometry.

Similarly, for experiments with the same but irradiated $\mathrm{Jak3}^{-/-}$ hosts, WT 2C donor cells showed markedly faster and more robust proliferation than $\mathrm{Cd} 25^{-/-} 2 \mathrm{C}$ counterparts (Figure 3B, bottom right two, and Supplementary Figure 3). The latter $C d 25^{-1-} 2 \mathrm{C}$ cells showed only slow rate of LIP comparable to that of both WT and $\mathrm{Cd} 25^{-1-} 2 \mathrm{C}$ donor cells in irradiated $\mathrm{Jak3}^{+/-}$hosts, indicating similar responses of these cells to IL-7 under this lymphopenic condition (Figure 3B, bottom left two). Together, these findings strongly suggest that the antigen-independent robust proliferation of naive $\mathrm{CD}^{+} \mathrm{T}$ cells in $\mathrm{Jak3}^{-/-}$hosts is heavily dependent on the direct engagement of both receptors CD25 and CD122 that are specific for only IL-2.

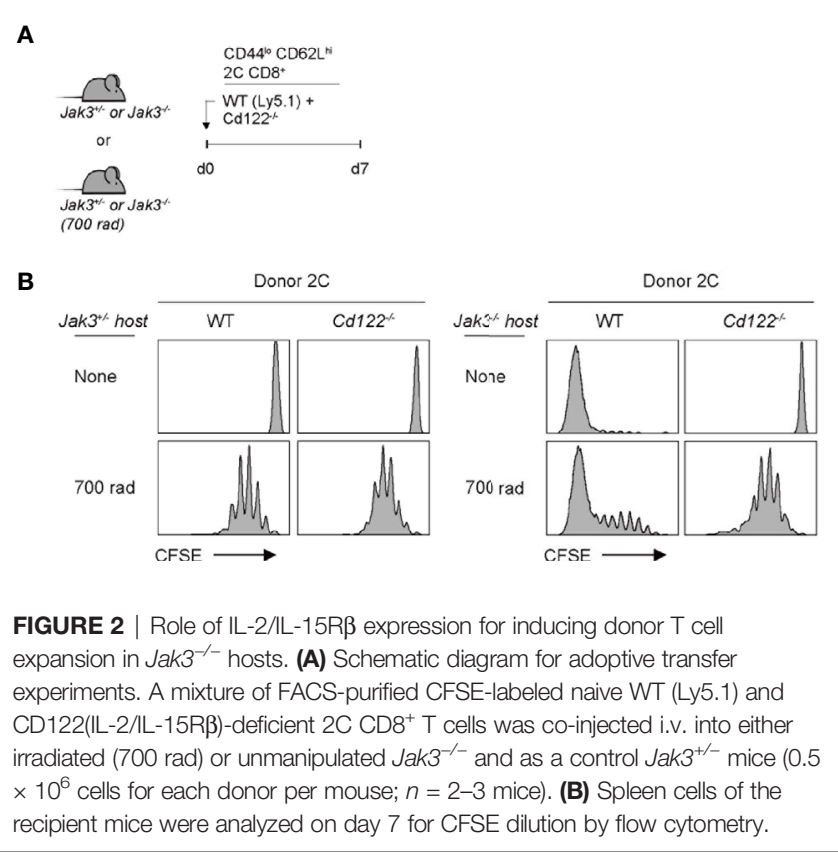

A

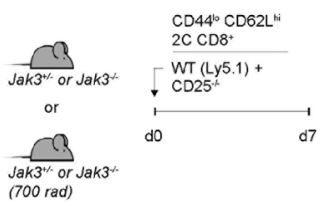

B

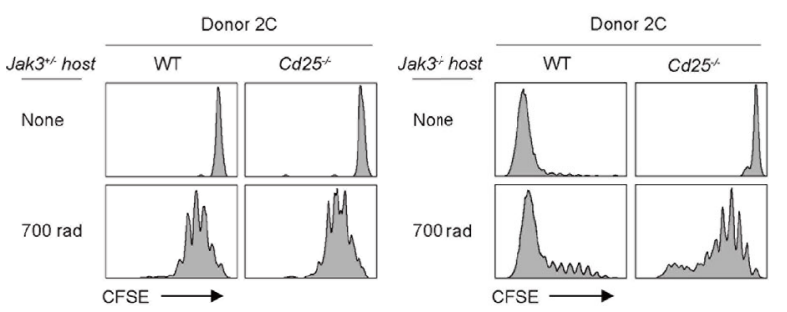

FIGURE 3 | Role of IL-2R $\alpha$ expression for inducing donor T cell expansion in

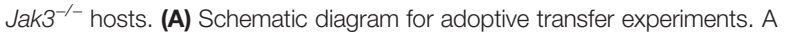
mixture of FACS-purified CFSE-labeled naive WT (Ly5.1) and CD25(IL-2R $\alpha$ )deficient $2 \mathrm{C} \mathrm{CD8}{ }^{+} \mathrm{T}$ cells was co-injected i.v. into either irradiated $(700 \mathrm{rad})$ or unmanipulated $\mathrm{Jak}^{-/-}$and as a control $\mathrm{Jak}^{+/-}$mice $\left(0.5 \times 10^{6}\right.$ cells for each donor per mouse; $n=2-3$ mice). (B) Spleen cells of the recipient mice were analyzed on day 7 for CFSE dilution by flow cytometry. 


\section{Role of CD4 ${ }^{+} \mathrm{T}$ Cells in High IL-2 Production in $\mathrm{Jak3}^{-/-}$Hosts}

Based on the aforementioned strict dependency on IL-2, we tested the in vivo levels of IL-2 in Jak3 ${ }^{-/-}$mice. For this purpose, serum samples were collected from WT and $J a k 3^{-/-}$mice, which were then analyzed for IL-2 detection using ELISA. As shown in Figure 4A, Jak $3^{-/-}$mice showed high serum levels of IL-2 compared to their WT counterparts. Consistent with this finding, Il2 mRNA expression levels were also markedly more enhanced in $\mathrm{Jak3}^{-/-}$spleen cells than in their WT counterparts (Figure 4B). Il15 mRNA levels were also tested and were no increase (but rather decreased) in $J a k 3^{-/-}$cells compared to WT counterparts (Supplementary Figure 4A), suggesting a negligible role of IL-15.

The direct requirement of IL-2 was also confirmed by an in vivo blocking experiment, in which $J a k 3^{-/-}$hosts were administered with a monoclonal antibody to either IL-2 or IL2 receptor beta-chain (clones JES6.1 and TM- $\beta 1$, respectively; Supplementary Figure 4B); the results clearly showed that the JES6. 1 and TM- $\beta 1$ injection (relative to PBS control) are both suppressive to a similar extent for the expansion of OT-I donor cells adoptively transferred into $\mathrm{Jak3}^{-/-}$hosts. These data, together with the aforementioned in vivo data with $2 \mathrm{C}$ donor cells lacking IL-2 receptors (i.e., CD25 and CD122) (Figures 2, 3), further support our conclusion that strong $\mathrm{T}$ cell proliferative responses are driven exclusively by higher concentrations of in vivo IL-2 present in $\mathrm{Jak3}^{-/-}$mice.
Given the rich supply of in vivo IL-2 in $J a k 3^{-/-}$mice, our prior data that, despite similar degree of cell divisions, WT 2C cells exhibited $~ 3-5$ times lower expansion in irradiated Jak3 ${ }^{-/-}$hosts than in non-irradiated counterparts (Figures 2, 3 and Supplementary Figures 2, 3) suggest a radiosensitive nature of IL-2-producing cells. With respect to the radiosensitive source of producing such high levels of IL-2 in vivo, the role of Jak3 $3^{-/-}$ $\mathrm{CD}^{+} \mathrm{T}$ cells was considered of particular importance, as these cells exhibited highly activated phenotypes (i.e., CD $44{ }^{\text {hi }}$ CD62L ${ }^{\text {lo }}$ ) and were shown to gradually accumulate in sufficient numberscomparable or even higher than those of WT controls-in $\mathrm{Jak}^{-/-}$ mice over time with age (9). In support of this, Il2 mRNA expression levels and in vivo IL-2 productions were higher in $\mathrm{Jak3}^{-/-} \mathrm{CD}^{+} \mathrm{T}$ cells than in their WT counterparts (Figures $4 \mathrm{C}$, D). To further confirm the possible role of $\mathrm{Jak3}^{-/-} \mathrm{CD} 4^{+} \mathrm{T}$ cells as a major source of high levels of in vivo IL-2, Jak3 ${ }^{-1-}$ mice were intraperitoneally administered a monoclonal antibody against CD4 for depleting host $\mathrm{CD}^{+} \mathrm{T}$ cell populations (clone GK1.5) for 7 days prior to starting adoptive transfer experiments (Figure 4E, top). The antibody-treated $\mathrm{Jak3}^{-/-}$mice were adoptively transferred with FACS-purified, CFSE-labeled OT-I naive CD8 ${ }^{+}$ $\mathrm{T}$ cells, and 5 days later, the proliferation of these cells was analyzed. Proliferation of OT-I donor cells was substantially reduced in GK1.5 mAb-treated Jak3 ${ }^{-/-}$hosts compared to control Ab-treated $\mathrm{Jak3}^{-/-}$hosts (Figure 4E, bottom, and Supplementary Figure 4C), suggesting a role for $\mathrm{Jak3}^{-/-} \mathrm{CD} 4^{+}$ $\mathrm{T}$ cells as an in vivo IL-2 resource.
A

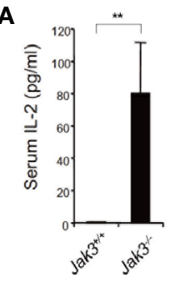

E
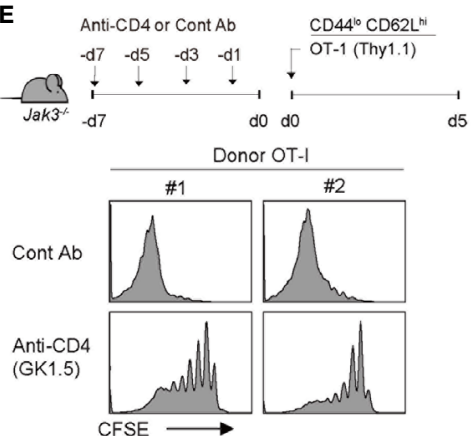

B

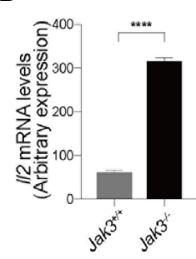

C

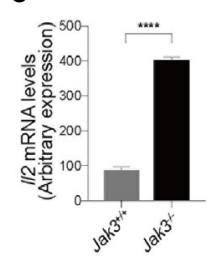

F

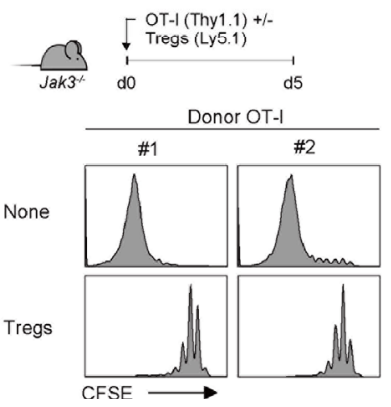

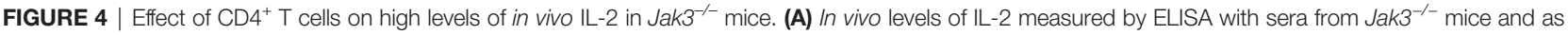

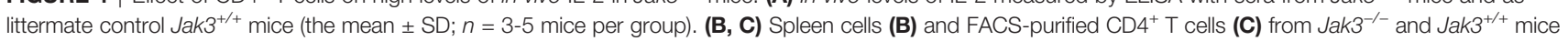

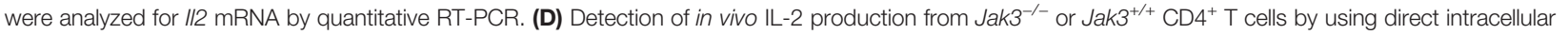
cytokine staining. (E) Jak3 ${ }^{-/-}$mice were injected i.p. with either anti-CD4 mAb (GK1.5) or as a control isotype lgG (total 4 injections every 2 days; $100 \mu \mathrm{g}$ per mouse; $n=2-4$ mice). The mice were injected i.v. with FACS-purified CFSE-labeled naive OT-I CD8 ${ }^{+}$T cells (Thy $1.1 ; 1 \times 10^{6}$ cells per mouse; $n=2-4$ mice). At day 5 after adoptive transfer, spleen cells of the recipient mice were analyzed for CFSE dilution by flow cytometry. (F) FACS-purified CFSE-labeled naive OT-I CD8 ${ }^{+} \mathrm{T}$ cells (Thy $1.1 ; 1 \times 10^{6}$ cells per mouse) were injected i.v. with or without CD4 ${ }^{+}$Tregs $\left(\sim 0.2 \times 10^{6}\right.$ cells per mouse) purified from Foxp3-GFP mice into Jak3 ${ }^{-/-}$mice $(n=2-$ 4 mice). Spleen cells of the recipient mice were analyzed on day 5 for CFSE dilution by flow cytometry. ${ }^{\star \star} P<0.01,{ }^{\star \star \star \star} P<0.0001$. 
Based on this role of in vivo IL-2, which is produced by activated $\mathrm{CD}^{+} \mathrm{T}$ cells in $\mathrm{Jak}^{-/-}$mice, we tested the effect of $\mathrm{CD} 4^{+}$Tregs, as this inhibitory $\mathrm{CD} 4^{+}$population is absent in $\mathrm{Jak} 3^{-/-}$ mice $(12,18)$. To this end, FACS-purified, CFSE-labeled OT-I naive $\mathrm{CD}^{+} \mathrm{T}$ cells were adoptively transferred with or without FACS-purified $\mathrm{CD}^{+}$Tregs (from Foxp3-GFP mice) into $\mathrm{Jak} 3^{-/-}$ hosts (Figure 4F, top). Proliferative responses of OT-I donor cells were markedly inhibited by the co-injection of Tregs compared to control non-injected Jak3 ${ }^{-/-}$hosts (Figure 4F, bottom, and Supplementary Figure 4D), and this finding was consistent with the prior notion that high level of CD25 expression on Tregs could deprive IL-2 from effector T cells and inhibit their proliferation by predominantly consuming IL-2 in vivo (30-32).

Collectively, these data indicate that $\mathrm{Jak3}^{-/-}$mice have a unique immune environment, where large numbers of activated $\mathrm{CD} 4^{+} \mathrm{T}$ cells (and conversely a scarcity of $\mathrm{CD} 4^{+}$Tregs) result in abnormally high levels of IL-2 production, which can induce the strong proliferation of adoptively transferred naive $\mathrm{T}$ cells in an antigen-independent manner.

\section{DISCUSSION}

$\mathrm{Jak3}^{-/-}$mice have been demonstrated to experience profound immunodeficiency, with developmental defects in various immune cell types, including $\mathrm{T}$ cells (both $\alpha \beta$ and $\gamma \delta \mathrm{T}$ cells), $B$ cells, and NK cells (9-11). These defects have been largely attributed to defective downstream signaling of Jak3-associated $\gamma_{c}$ cytokines, particularly IL-7 and IL-15 (6-8). In addition, defective IL-2 signaling of Jak3-deficient mice leads to Treg deficiency, which is consistent with mice lacking IL-2 or its receptor components (i.e., CD25, CD122, and CD132) (12, 33, 34). Although the latter is associated with the gradual accumulation of activated $\mathrm{CD}^{+} \mathrm{T}$ cell populations in $\mathrm{Jak3}^{-1-}$ mice $(9,10,17)$, its physiological impacts remain unclear. Here, we demonstrated a previously unidentified phenotype of Jak3deficient mice by showing that $J a k 3^{-l-} \mathrm{CD} 4^{+} \mathrm{T}$ cells produced extremely high amounts of IL-2 in vivo, and consequently, adoptively transferred naive $\mathrm{T}$ cells could undergo a rapid and intense form of antigen-independent proliferation. Notably, this type of proliferation-even though antigen-independent-was still influenced by the intrinsic TCR affinity/avidity for selfligands. Such self-dependency was in close agreement with previous findings demonstrating strong IL-2-driven $\mathrm{T}$ cell proliferation both in vitro and in vivo $(19,20)$. Therefore, our findings reveal a unique immune context, i.e., supraphysiological levels of in vivo IL-2, of Jak3-deficient mice and further strengthen the prevailing notion that even a single $\gamma_{c}$ cytokine (IL-2) plays a crucial role in promoting massive bystander expansions of naive $\mathrm{T}$ cell populations.

The strong proliferation of adoptively transferred naive CD ${ }^{+}$ $\mathrm{T}$ cells observed in $\mathrm{Jak3}^{-/-}$mice closely resembles those observed in mice lacking CD122 (IL-2 receptor beta, IL-2R $\beta$ ) and CD132 (common $\gamma_{c}$ receptor) in terms of their tempo and robustness as well as strict dependency on two stimuli, namely $\gamma_{c}$ cytokines and TCR contacts with self-ligands $(19,35)$. However, the difference was the type of cytokines involved; while IL-2 is a major driver in Jak3 ${ }^{-/-}$mice, mixtures of 2-3 $\gamma_{c}$ cytokines-either IL-2 and IL-15 or IL-7, IL-2, and IL-15-act as stimulators in $C d 122^{-/-}$and $C d 132^{-/-}$mice, respectively. Moreover, the reason for such enhanced levels of these cytokines in $C d 122^{-/-}$and $C d 132^{-/-}$ mice was largely accounted for by the lack of the receptors involved in specific binding to either IL-2 and IL-15 (for Cd122 $2^{-/-}$ mice) or IL-7, IL-2, and IL-15 (for Cd132 $2^{-/-}$mice), thereby leading to in vivo accumulation of cytokines that would otherwise be consumed $(19,35)$. In this regard, high levels of in vivo IL-2 in Jak $3^{-/-}$mice was odd at first glance, since these mice have a defect not in the IL-2 receptors but in the downstream signaling. However, based on our data showing the reduced $\mathrm{T}$ cell expansion caused by $\mathrm{CD}^{+} \mathrm{T}$ cell depletion (using GK1.5 mAb) and co-transfer with Tregs, we propose that $\mathrm{CD} 4^{+} \mathrm{T}$ cells in $\mathrm{Jak}^{-/-}$mice are overtly activated-presumably by their uncontrolled reactivity to self-antigens-due to the lack of Tregs, which in turn produces IL-2 markedly beyond a physiological level that is sufficient for stimulating intense proliferative responses of adoptively transferred naive $\mathrm{CD} 8^{+} \mathrm{T}$ cells. Whether prior Tregs reconstitution can restore abnormal immune contexts (i.e., high levels of in vivo IL-2) of Jak3-deficient mice will thus be interesting to address in future studies.

Despite a few cases of $J a k 3$ mutations in humans, whether the phenomenon observed in $J a k 3^{-/-}$mice is similarly reproduced in clinical patients lacking functional Jak3 remains elusive. In this regard, clinical cases, albeit a few, showing that activated/ memory $\mathrm{T}$ cells have been associated with Jak3 mutations support this possibility $(36,37)$. Nevertheless, the majority of patients with defective Jak3 are associated with severe combined immunodeficiency and thus compounding effects due to increased susceptibility to infection cannot be easily excluded (13-16, 38). In summary, our results further extend our understanding of the physiological impact of Jak3 deficiency, which can cause the uncontrolled activation and accumulation of self-reactive $\mathrm{CD}^{+}{ }^{+} \mathrm{T}$ cells and accordingly abnormally high levels of in vivo IL-2 production. These findings also have an implication for rationale treatment strategies for patients with a loss-offunction Jak3 mutation-especially those concerning graftversus-host reaction from transplacentally acquired maternal or donor allogeneic $\mathrm{T}$ cells after bone marrow transfusions.

\section{DATA AVAILABILITY STATEMENT}

The raw data supporting the conclusions of this article will be made available by the authors, without undue reservation.

\section{ETHICS STATEMENT}

The animal study was reviewed and approved by Animal Experimental and Ethic Committee of the Chonnam National University. 


\section{AUTHOR CONTRIBUTIONS}

G-WL performed all major experiments. G-WL and J-HC designed experiments and analyzed and interpreted the data. S-WL, JK, and Y-JJ helped some experiments, and C-HY and HOK contributed to this study with valuable discussion and comments. G-WL and J-HC wrote the manuscript. All authors contributed to the article and approved the submitted version.

\section{FUNDING}

This work was supported by National Research Foundation funded by the Korean Ministry of Science and ICT (2018R1A5A2024181 and 2020M3A9G3080281 for J-HC).

\section{REFERENCES}

1. Ihle JN, Kerr IM. Jaks and Stats in signaling by the cytokine receptor superfamily. Trends Genet (1995) 11(2):69-74. doi: 10.1016/S0168-9525(00) 89000-9

2. Lin JX, Leonard WJ. The Common Cytokine Receptor gamma Chain Family of Cytokines. Cold Spring Harb Perspect Biol (2018) 10(9):1-37. doi: 10.1101/ cshperspect.a028449

3. Thomis DC, Berg LJ. The role of Jak3 in lymphoid development, activation, and signaling. Curr Opin Immunol (1997) 9(4):541-7. doi: 10.1016/S09527915(97)80108-2

4. Leonard WJ. Role of Jak kinases and STATs in cytokine signal transduction. Int J Hematol (2001) 73(3):271-7. doi: 10.1007/BF02981951

5. Ghoreschi K, Laurence A, O’Shea JJ. Janus kinases in immune cell signaling. Immunol Rev (2009) 228(1):273-87. doi: 10.1111/j.1600-065X.2008.00754.X

6. Cao X, Shores EW, Hu-Li J, Anver MR, Kelsall BL, Russell SM, et al. Defective lymphoid development in mice lacking expression of the common cytokine receptor gamma chain. Immunity (1995) 2(3):223-38. doi: 10.1016/10747613(95)90047-0

7. DiSanto JP, Muller W, Guy-Grand D, Fischer A, Rajewsky K. Lymphoid development in mice with a targeted deletion of the interleukin 2 receptor gamma chain. Proc Natl Acad Sci U S A (1995) 92(2):377-81. doi: 10.1073/ pnas.92.2.377

8. Leonard WJ, Shores EW, Love PE. Role of the common cytokine receptor gamma chain in cytokine signaling and lymphoid development. Immunol Rev (1995) 148:97-114. doi: 10.1111/j.1600-065X.1995.tb00095.x

9. Thomis DC, Gurniak CB, Tivol E, Sharpe AH, Berg LJ. Defects in B lymphocyte maturation and $\mathrm{T}$ lymphocyte activation in mice lacking Jak3. Science (1995) 270(5237):794-7. doi: 10.1126/science.270.5237.794

10. Nosaka T, van Deursen JM, Tripp RA, Thierfelder WE, Witthuhn BA, McMickle AP, et al. Defective lymphoid development in mice lacking Jak3. Science (1995) 270(5237):800-2. doi: 10.1126/science.270.5237.800

11. Baird AM, Thomis DC, Berg LJ. T cell development and activation in Jak3deficient mice. J Leukoc Biol (1998) 63(6):669-77. doi: 10.1002/jlb.63.6.669

12. Fontenot JD, Rasmussen JP, Gavin MA, Rudensky AY. A function for interleukin 2 in Foxp3-expressing regulatory T cells. Nat Immunol (2005) 6 (11):1142-51. doi: 10.1038/ni1263

13. Russell SM, Tayebi N, Nakajima H, Riedy MC, Roberts JL, Aman MJ, et al. Mutation of Jak3 in a patient with SCID: essential role of Jak3 in lymphoid development. Science (1995) 270(5237):797-800. doi: 10.1126/ science.270.5237.797

14. Macchi P, Villa A, Giliani S, Sacco MG, Frattini A, Porta F, et al. Mutations of Jak-3 gene in patients with autosomal severe combined immune deficiency (SCID). Nature (1995) 377(6544):65-8. doi: 10.1038/377065a0

15. Candotti F, Oakes SA, Johnston JA, Giliani S, Schumacher RF, Mella P, et al. Structural and functional basis for JAK3-deficient severe combined immunodeficiency. Blood (1997) 90(10):3996-4003. doi: 10.1182/ blood.V90.10.3996

\section{ACKNOWLEDGMENTS}

We thank Kwangsoon Kim, Sinhyeog Im, Youjeong Lee, and Seongwoo Lee (POSTECH) for providing various transgenic and knock-out mice indicated; Minju Ryu and Sunmi An (CNU) for administrative assistance; POSTECH and CNU flow cytometric core facilities for assistance with cell sorting; and Myoungsook Kim (CNU) for mice breeding and care.

\section{SUPPLEMENTARY MATERIAL}

The Supplementary Material for this article can be found online at: https://www.frontiersin.org/articles/10.3389/fimmu.2020.616898/ full\#supplementary-material

16. Casanova JL, Holland SM, Notarangelo LD. Inborn errors of human JAKs and STATs. Immunity (2012) 36(4):515-28. doi: 10.1016/j.immuni.2012.03.016

17. Park SY, Saijo K, Takahashi T, Osawa M, Arase H, Hirayama N, et al. Developmental defects of lymphoid cells in Jak3 kinase-deficient mice. Immunity (1995) 3(6):771-82. doi: 10.1016/1074-7613(95)90066-7

18. Yao Z, Kanno Y, Kerenyi M, Stephens G, Durant L, Watford WT, et al. Nonredundant roles for Stat5a/b in directly regulating Foxp3. Blood (2007) 109(10):4368-75. doi: 10.1182/blood-2006-11-055756

19. Cho JH, Boyman O, Kim HO, Hahm B, Rubinstein MP, Ramsey C, et al. An intense form of homeostatic proliferation of naive CD8+ cells driven by IL-2. J Exp Med (2007) 204(8):1787-801. doi: 10.1084/jem.20070740

20. Kim J, Lee JY, Cho K, Hong SW, Kim KS, Sprent J, et al. Spontaneous Proliferation of CD4(+) T Cells in RAG-Deficient Hosts Promotes AntigenIndependent but IL-2-Dependent Strong Proliferative Response of Naive CD8 (+) T Cells. Front Immunol (2018) 9:1907. doi: 10.3389/fimmu.2018.01907

21. Hosking MP, Flynn CT, Whitton JL. Antigen-specific naive CD8+ T cells produce a single pulse of IFN-gamma in vivo within hours of infection, but without antiviral effect. J Immunol (2014) 193(4):1873-85. doi: 10.4049/jimmunol.1400348

22. Goldrath AW, Bevan MJ. Low-affinity ligands for the TCR drive proliferation of mature CD8+ T cells in lymphopenic hosts. Immunity (1999) 11(2):183-90. doi: 10.1016/S1074-7613(00)80093-X

23. Kieper WC, Burghardt JT, Surh CD. A role for TCR affinity in regulating naive T cell homeostasis. J Immunol (2004) 172(1):40-4. doi: 10.4049/jimmunol.172.1.40

24. Azzam HS, Grinberg A, Lui K, Shen H, Shores EW, Love PE. CD5 expression is developmentally regulated by T cell receptor (TCR) signals and TCR avidity. J Exp Med (1998) 188(12):2301-11. doi: 10.1084/jem.188.12.2301

25. Mandl JN, Monteiro JP, Vrisekoop N, Germain RN. T cell-positive selection uses self-ligand binding strength to optimize repertoire recognition of foreign antigens. Immunity (2013) 38(2):263-74. doi: 10.1016/j.immuni.2012.09.011

26. Surh CD, Sprent J. Homeostasis of naive and memory $\mathrm{T}$ cells. Immunity (2008) 29(6):848-62. doi: 10.1016/j.immuni.2008.11.002

27. Seddon B, Zamoyska R. TCR and IL-7 receptor signals can operate independently or synergize to promote lymphopenia-induced expansion of naive T cells. $J$ Immunol (2002) 169(7):3752-9. doi: 10.4049/jimmunol.169.7.3752

28. Min B, Yamane H, Hu-Li J, Paul WE. Spontaneous and homeostatic proliferation of CD4 $\mathrm{T}$ cells are regulated by different mechanisms. $J$ Immunol (2005) 174(10):6039-44. doi: 10.4049/jimmunol.174.10.6039

29. Bosco N, Agenes F, Ceredig R. Effects of increasing IL-7 availability on lymphocytes during and after lymphopenia-induced proliferation. J Immunol (2005) 175(1):162-70. doi: 10.4049/jimmunol.175.1.162

30. Pandiyan P, Zheng L, Ishihara S, Reed J, Lenardo MJ. CD4+CD25+Foxp3+ regulatory $\mathrm{T}$ cells induce cytokine deprivation-mediated apoptosis of effector CD4+ T cells. Nat Immunol (2007) 8(12):1353-62. doi: 10.1038/ni1536

31. Schmidt A, Oberle N, Krammer PH. Molecular mechanisms of treg-mediated T cell suppression. Front Immunol (2012) 3:51. doi: 10.3389/fimmu.2012.00051

32. Chinen T, Kannan AK, Levine AG, Fan X, Klein U, Zheng Y, et al. An essential role for the IL-2 receptor in Treg cell function. Nat Immunol (2016) 17 (11):1322-33. doi: 10.1038/ni.3540 
33. Suzuki H, Kundig TM, Furlonger C, Wakeham A, Timms E, Matsuyama T, et al. Deregulated $\mathrm{T}$ cell activation and autoimmunity in mice lacking interleukin-2 receptor beta. Science (1995) 268(5216):1472-6. doi: 10.1126/ science. 7770771

34. Willerford DM, Chen J, Ferry JA, Davidson L, Ma A, Alt FW. Interleukin-2 receptor alpha chain regulates the size and content of the peripheral lymphoid compartment. Immunity (1995) 3(4):521-30. doi: 10.1016/1074-7613(95) 90180-9

35. Ramsey C, Rubinstein MP, Kim DM, Cho JH, Sprent J, Surh CD. The lymphopenic environment of CD132 (common gamma-chain)-deficient hosts elicits rapid homeostatic proliferation of naive T cells via IL-15. J Immunol (2008) 180(8):5320-6. doi: 10.4049/jimmunol.180.8.5320

36. Frucht DM, Gadina M, Jagadeesh GJ, Aksentijevich I, Takada K, Bleesing JJ, et al. Unexpected and variable phenotypes in a family with JAK3 deficiency. Genes Immun (2001) 2(8):422-32. doi: 10.1038/sj.gene.6363802

37. Cattaneo F, Recher M, Masneri S, Baxi SN, Fiorini C, Antonelli F, et al. Hypomorphic Janus kinase 3 mutations result in a spectrum of immune defects, including partial maternal T-cell engraftment. J Allergy Clin Immunol (2013) 131(4):1136-45. doi: 10.1016/j.jaci.2012.12.667

38. Roberts JL, Lengi A, Brown SM, Chen M, Zhou YJ, O'Shea JJ, et al. Janus kinase 3 (JAK3) deficiency: clinical, immunologic, and molecular analyses of 10 patients and outcomes of stem cell transplantation. Blood (2004) 103 (6):2009-18. doi: 10.1182/blood-2003-06-2104

Conflict of Interest: The authors declare that the research was conducted in the absence of any commercial or financial relationships that could be construed as a potential conflict of interest.

Copyright $\odot 2021$ Lee, Lee, Kim, Ju, Kim, Yun and Cho. This is an open-access article distributed under the terms of the Creative Commons Attribution License (CC BY). The use, distribution or reproduction in other forums is permitted, provided the original author(s) and the copyright owner(s) are credited and that the original publication in this journal is cited, in accordance with accepted academic practice. No use, distribution or reproduction is permitted which does not comply with these terms. 